\title{
RANCANG BANGUN APLIKASI TATA KELOLA DESA BERBASIS WEB MENGGUNAKAN METODE WATERFALL DI KANTOR DESA SEPUKUR
}

\author{
M. Julkarnain ${ }^{1}$, Herfandi ${ }^{2}$, Deri Afriliyansa ${ }^{3}$ \\ 1,2,3 Teknik Informatika, Universitas Teknologi Sumbawa \\ email: m.julkarnain@uts.ac.id ${ }^{1}$
}

\begin{abstract}
Abstrak: Penelitian ini bertujuan untuk merancang dan membangun aplikasi tata kelola desa berbasis web menggunakan metode waterfall di kantor Desa Sepukur. Model pengembangan aplikasi ini menyempurnakan sistem sebelumnya untuk nantinya digunakan oleh pihak Desa Sepukur. Sistem ini dirancang dan dibangun menggunakan bahasa pemrograman PHP dengan framework codeigneter dan database MySQL. Adapun metode pengembangan perangkat lunak yaitu menggunakan metode waterfall dan menggunakan metode kualitatif untuk metode pengumpulan data. Metode pengujian dilakukan melalui metode black-box testing yaitu pengujian dilakukan berdasarkan fungsionalitas. Dalam rancang bangun aplikasi tata kelola desa berbasis web di kantor Desa Sepukur memiliki beberapa pengelolaan yaitu pengelolaan surat menyurat, kependudukan dan pengarsipan surat. aplikasi tata kelola desa berbasis web ini diharapkan dapat membantu pemerintah desa dalam memberikan pelayanan surat secara cepat serta dapat meminimalisir kehilangan dan kerusakan surat
\end{abstract}

Kata kunci: codeigneter , php, tata kelola desa, web, waterfall.

\begin{abstract}
This study research to design and build a web-based village governance application by using the Waterfall method at the Sepukur village office. This application development model enhances the previous system for later use by the Sepukur Village office. This system is designed and built using the PHP programming language with Codeigniter framework and MySQL database. The software development method uses the waterfall method and qualitative for data collection methods. The test method is carried out through black-box testing, namely testing carried out, namely testing carried out based on functionality. In designing a web-Sepukur village governance application in Sepukur Village, it has several management, namely managing correspondence, population, and letter archiving. This web-based village management application is expected to be able to assist the village government in providing mail services quickly and can minimize letter loss and damage.
\end{abstract}

Keywords: codeigneter, php, village governance, web, waterfall. 


\section{PENDAHULUAN}

Desa Sepukur merupakan salah satu desa yang terletak di Kecamatan Lantung, Kabupaten Sumbawa, Provinsi Nusa Tenggara Barat. Tata kelola desa yang dilakukan di Kantor Desa Sepukur memiliki beberapa macam pengelolaan yaitu pengarsipan surat masuk dan surat keluar, pelayanan pembuatan surat masyarakat, pendataan penduduk dan lain sebagainya.

Dari data yang diperoleh di lapangan menunjukkan bahwa sistem tata kelola desa di Kantor Desa Sepukur belum terkomputerisasi. Pada pengelolaan penyimpanan surat keluar dan surat masuk, petugas desa terlebih dahulu mencatat nomor surat dibuku besar, setelah itu surat akan disimpan di lemari arsip dalam jangka waktu yang lama, sehingga surat seringkali rusak dan hilang. Pada pelayanan pembuatan surat masyarakat desa, petugas desa masih menggunakan file yang disimpan di dalam laptop sehingga petugas terlebih dahulu akan mencari format file yang akan digunakan. Selain daripada itu, surat yang akan dibuat harus sesuai dengan data-data penduduk yang ada.

Dilihat dari permasalahan diatas, pada pembuatan surat masyarakat desa, petugas desa tidak lagi dipersulit oleh penyesuain keperluan surat dan data penduduk yang begitu lama (seperti pada contoh kasus masalah), karena surat-surat sudah terintegrasi dengan data kependudukan. hanya dengan mencari Nomor Induk Kependudukan (NIK) yang telah dimasukan didalam sistem, lalu petugas desa memilih opsi pelayanan sesuai keperluan penduduk. petugas desa juga lebih mudah dalam pengarsipan berbagai surat, cukup dengan scan surat terlebih dahulu lalu dilakukan proses upload ke dalam sistem maka surat akan langsung terarsip di dalam sistem. Sehingga ketika dibutuhkan, surat yang telah diarsip dengan mudah dipanggil dan di cetak kembali.

\section{TINJAUAN PUSTAKA}

Pada penelitian ini penulis memiliki beberapa referensi terkait judul Aplikasi Tata Kelola Desa Berbasis Web yaitu Pada penelitian ini penulis memiliki beberapa referensi terkait judul Aplikasi Tata Kelola Desa Berbasis Web yang berjudul Aplikasi Pelayanan Surat Menyurat Desa Tanah Putih Berbasis Web. Dalam jurnal tersebut dijelaskan bahwa masyarakat dapat membuat permohonan surat secara online dan dapat mengetahui apakah surat tersebut telah selesai dibuat dan dapat diambil, sehingga menghemat waktu dan biaya transportasi dan membantu meringankan masyarakat di Desa Tanah Putih dalam mengurus berbagai keperluan, seperti untuk pelayanan di rumah sakit dan beasiswa [1]. Rancang Bangun Aplikasi Kependudukan Berbasis Web Di Desa Kedungrejo Waru-Sidoarjo. Dalam jurnal tersebut menjelaskan bahwa aplikasi kependudukan membantu dan mempermudah pencarian informasi kependudukan. Selain itu juga dapat mencegah terjadinya penumpukan file dan memperkecil ruang penyimpanan sehingga memudahkan pihak desa atau kelurahan dalam pengoperasiannya dan memperkecil kesalahan yang mungkin terjadi serta memudahkan dalam pembuatan laporan kependudukan [2]. Pengembangan Sistem Informasi Administrasi Desa Terpadu pada Desa Karoya Kabupaten Purwakarta. Menjelaskan bahwa pengembangan pada sistem informasi administrasi ini mempermudah, mempercepat dan memperlancar informasi Kependudukan pada Desa Karoya, Kecamatan Tegalwaru, Kabupaten Purwakarta khususnya bagi Kaur Administrasi untuk memantau perkembangan data jumlah penduduk [3]. Rancang Bangun Sistem Informasi Data Kependudukan di Desa Katerban Kecamatan Baron Nganjuk. menjelaskan bahwa sistem yang dibangun akan memudahkan perangkat desa dalam mengarsipkan dan mengelola data kependudukan [4]. Perancangan Sistem Informasi Permohonan Surat Online "Sipadu" Di Tingkat Kecamatan Berbasis Web. Menjelaskan bahwa aplikasi ini bertujuan untuk merancang sistem yang dapat membantu masyarakat dalam pengajuan surat secara online dan memudahkan pengarsipan di kantor kecamatan [5].

CodeIgniter merupakan framework aplikasi web terbuka yang digunakan untuk membangun aplikasi PHP dinamis. Tujuan utama framework ini agar pengembang bekerja secara cepat tanpa perlu menulis ulang kode [6].

Unified modeling language (UML) adalah Bahasa untuk menspesifikasi, memvisualisasikan, serta mengonstruksikan bangun dasar sistem perangkat lunak, termasuk melibatkan pemodelan aturan-aturan bisnis [7]

UML memiliki beberapa jenis yaitu use case diagram, class diagram, sequence diagram dan activity diagram. Berikut penjelasan tentang definisi dari beberapa jenis UML [8].

Metode yang digunakan dalam peneitian ini adalah metode waterfall, metode ini dipilih karena bersifat sistematis serta kebutuhan data yang akan digunakan pada penelitian ini sudah ada. Adapun tahapan dari metode waterfall adalah sebagai berikut [9]:

\section{Requirements Analysis and Definition}

Tahap pertama adalah Requirements Analysis and Definition Pada tahap ini peneliti melakukan analisa terhadap kebutuhan software, kebutuhan hardware, kebutuhan pengguna dan kebutuhan data. Tujuannya agar dalam perancangan dan pembangunan aplikasi dapat sesuai dengan spesifikasi yang dibutuhkan.

\section{System and Software Design}


Tahap kedua adalah System and Software Design Pada tahap ini, dilakukan perancangan terhadap sistem, basis data, dan user interface. Dalam hal ini peneliti menggunakan Unified Modeling System (UML) untuk pemodelan sistem.

\section{Implementation and Unit Testing}

Tahap ketiga adalah Implementation and Unit Testing dilakukan Setelah perancangan software design selesai, dilakukan pengkodean agar perancangan perangkat lunak direalisasikan sebagai serangkaian program atau unit program. Dalam hal ini penulis melakukan pengkodean menggunakan Bahasa pemrograman PHP, HTML dan CSS serta Codeigneter sebagai framework.

\section{Integration and System Testing}

Tahap keempat adalah Integration and System Testing, pada tahap ini peneliti melakukan pengujian terhadap sistem yang telah dibangun. Dalam hal ini peneliti melakukan pengujian menggunakan BlackBox testing. Tujuannya untuk memastikan apakah sistem sudah sesuai dengan kebutuhan perangkat lunak atau tidak.

\section{Operation and Maintenance}

Tahap kelima adalah Operation and Maintenance dilakukan setelah program berhasil diuji dan layak digunakan, maka aplikasi akan diserahkan kepada pihak yang terkait objek penelitian skripsi ini, setelah itu dalam kurun waktu tertentu peneliti akan melakukan pemeliharaan sistem secara berkala.

\section{METODE PENELITIAN}

peneliti menggunakan proses pengumpulan data dan metode pengembangan perangkat lunak. Adapun tahapan-tahapan yang digunakan dalam penelitian ini adalah sebagai berikut:

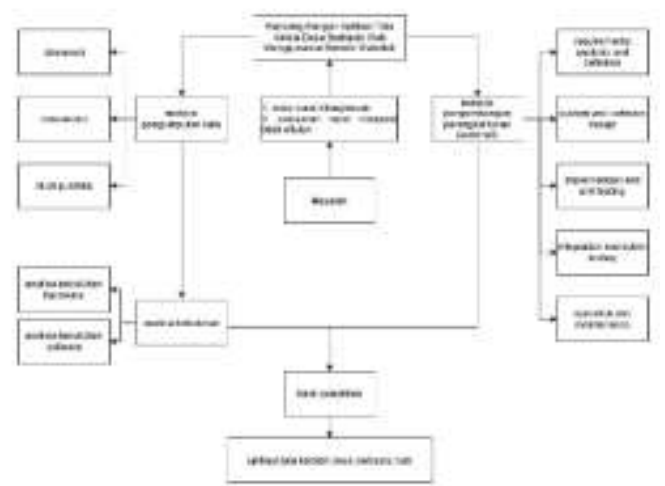

Gambar 1. Alur Penelitian

Metode pengumpulan data yang digunakan dalam penelitian ini adalah metode pendekatan kualitatif, dikarenakan Peneliti terjun ke lapangan, mempelajari suatu proses atau penemuan yang tenjadi secara alami, mencatat, menganalisis, menafsirkan dan melaporkan serta menarik kesimpulan-kesimpulan dari proses tersebut.

\section{Observasi}

Pada tahap ini peneliti melakukan survey langsung di Kantor Desa Sepukur untuk mengumpulkan data-data yang berkaitan dengan proses pengelolaan data dan pelayanan masyarakat Desa Sepukur.

\section{Wawancara}

Metode wawancara dilakukan untuk mengumpulkan data secara langsung dengan cara melakukan tanya jawab dengan narasumber, penelitian melakukan wawancara dengan bapak Mustahar M. Sidik selaku Kepala Desa Sepukur mengenai masalah yang dialami dalam proses pengolahan data serta pelayanan kepada masyarakat desa.

\section{Studi Pustaka}

Dilakukan dengan cara memperhatikan referensi atau literatur yang mendukung dalam penyusunan skripsi ini, data informasi yang diambil dari pengumpulan data ini adalah dasar-dasar teori, yang bersumber dari buku, jurnal, skripsi serta dokumen yang berhubungan dengan aplikasi yang akan dibangun.

\section{HASIL DAN PEMBAHASAN}

Berdasarkan hasil observasi dan wawancara yang yang dilakukan oleh peneliti terhadap sistem berjalan pada proses pelayanan surat menyurat kepada masyarakat desa serta pengarsipan terhadap surat masuk dan surat keluar di Kantor Desa Sepukur menggambarkan bahwa sistem yang sedang berjalan masih bersifat manual sehingga menimbulkan beberapa masalah baik dalam efektifitas waktu pelayanan dan keamanan pengarsipan surat.

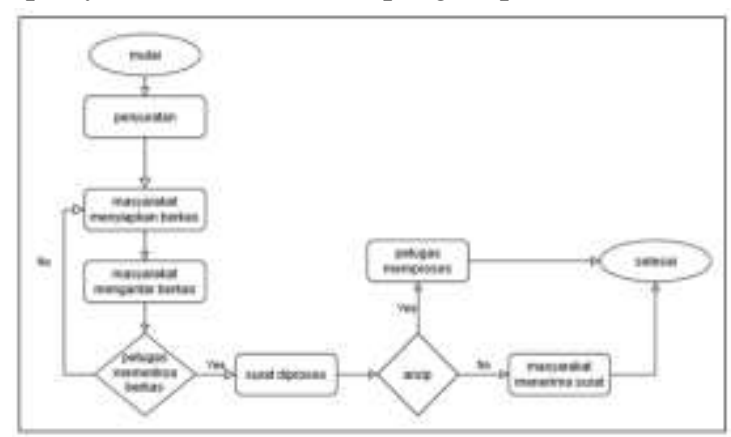

Gambar 2. Flowchart Sistem Berjalan

Sistem usulan merupakan suatu sistem yang ditawarkan untuk mempebaharui sistem sebelumnya yang awalnya melakukan pengelolaan dengan cara manual akan diperbaharui menjadi terkomputerisasi sehingga memudahkan petugas dalam memberikan pelayanan yang lebih efektif. Berikut gambaran dan penjelasannya: 


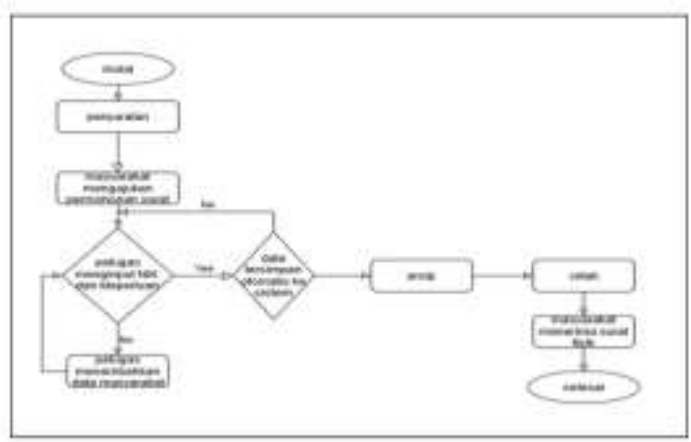

Gambar 3. Flowchart Sistem Usulan

\section{Use Case Diagram}

Berikut gambar dan penjelasannya:

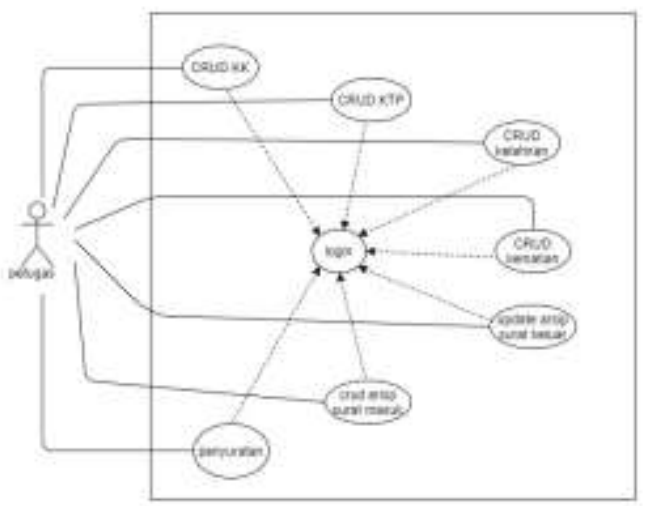

Gambar 4. Use Case Diagram

Berdasarkan gambar diatas, seorang petugas dapat melakukan beberapa pengelolaan. akan tetapi, sebelum melakukan proses tersebut petugas diharuskan untuk melakukan login terlebih dahulu. Setelah login berhasil, petugas dapat mengelolah beberapa pengelolaan yaitu pengelolan pada penyuratan, pengelolaan data penduduk yang meliputi kartu tanda penduduk (KTP), kartu keluarga (KK), data kelahiran, dan data kematian serta pengelolaan arsip surat yang meliputi surat keluar dan surat masuk.

\section{Activity Diagram Penyuratan}

berikut gambar dan penjelasan Activity Diagram Penyuratan:

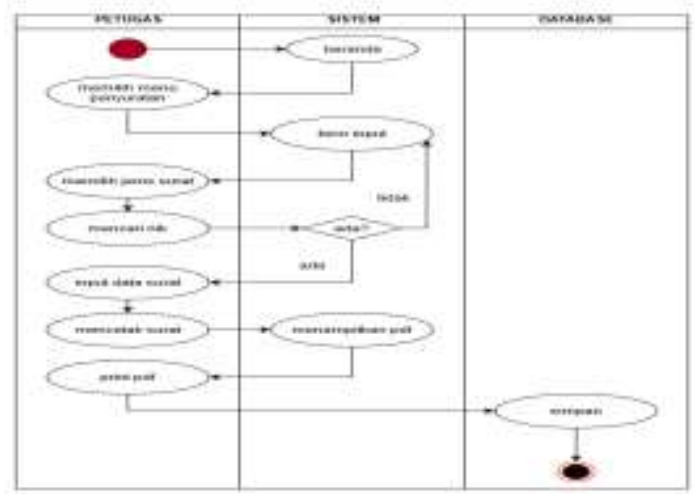

Pada gambar diatas menggambarkan bahwa saat petugas ingin membuat surat, petugas memilih mеnи penyuratan maka akan tampil form input surat, setelah itu petugas akan memilih jenis surat lalu memasukkan NIK, sistem akan melakukan validasi apakah data NIK sudah terdata di dalam sistem atau belum, jika belum maka surat tidak bisa dicetak jika sudah terdata maka petugas akan melanjutkan untuk melakukan input data surat selanjut mencetak surat dalam bentuk $p d f$ selanjutnya petugas akan mencetak surat dan data surat secara otomatis tersimpan di dalam database.

\section{Sequence Diagram Penyuratan}

Berikut Berikut gambar dan penjelasannya:

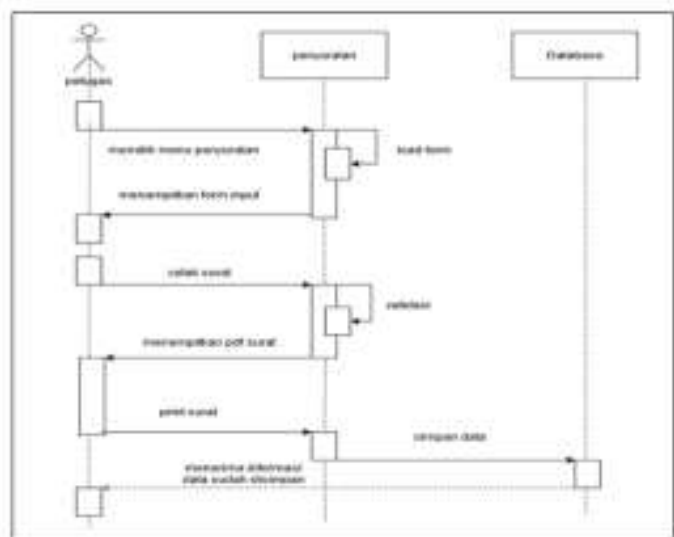

Gambar 5. Sequence Diagram Penyuratan

Pada gambar diatas proses dimulai yaitu pada saat petugas memilih menu penyuratan maka sistem akan menampilkan halaman mепи penyuratan, petugas melakukan input data ke dalam sistem, setelah itu petugas memilih cetak disistem, sistem menampilkan $p d f$ dan petugas mencetak surat, selanjutnya sistem secara otomatis menyimpan ke database dan petugas menerima informasi simpan dari sistem.

\section{Rancangan Halaman Login}

halaman login merupakan halaman awal pada saat admin mengakses aplikasi web tata kelola desa. di halaman login admin harus memasukkan username dan password agar dapat mengelolah aplikasi web Adapun gambar dan penjelasannya:

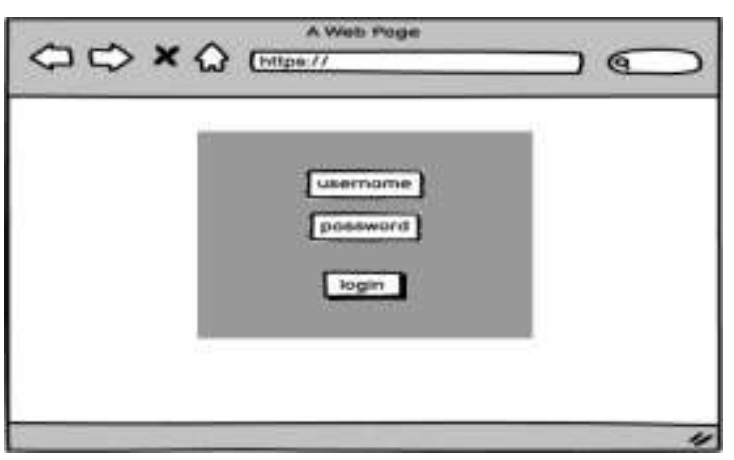

Gambar 6. Perancangan Halaman Login

\section{Rancangan Halaman Beranda}


halaman beranda merupakan halaman utama pada saat user berhasil login ke dalam sistem. berikut gambar dan penjelasannya:

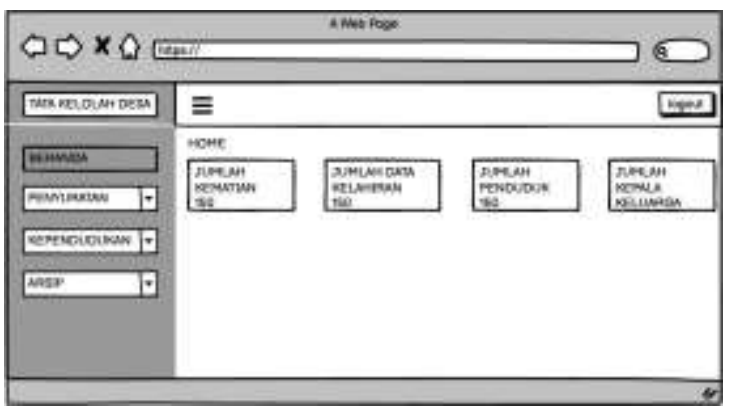

Gambar 7. Halaman Beranda

\section{Rancangan Halaman Penyuratan}

Halaman penyuratan merupakan halaman yang berfungsi untuk mengelolah/mencetak surat. berikut gambar dan penjelasannya:

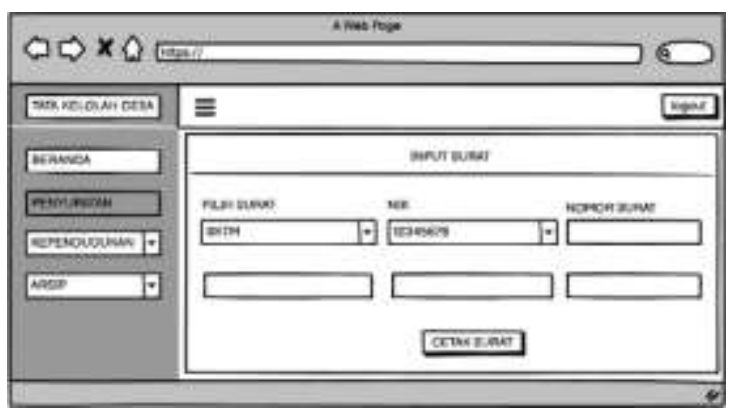

Gambar 8. Halaman Penyuratan

\section{Implementasi Program}

Implementasi program adalah tahap penerapan program yang telah dibangun sesuai dengan perancangan sistem yang telah dirancang sebelumnya. Adapun implementasi aplikasi Tata Kelolah Desa Berbasis Web di Kantor Desa Sepukur sebagai berikut:

\section{Implementasi Halaman Login}

Halaman login merupakan halaman awal pada saat petugas mengakses aplikasi web tata kelolah desa. Adapun gambar dan penjelasannya sebagai berikut:

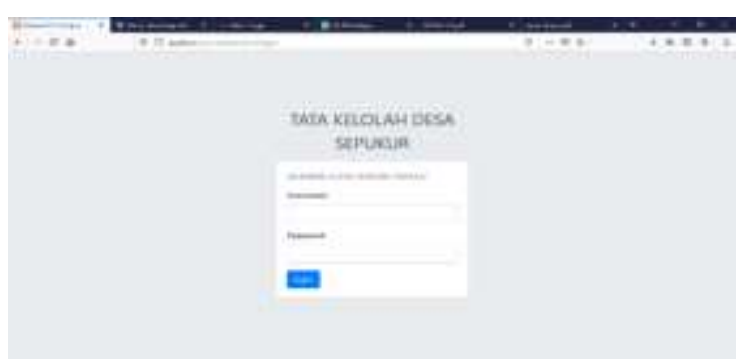

Gambar 8. Implementasi Halaman Login

\section{Implementasi Halaman Beranda}

Beranda merupakan halaman awal yang muncul pada saat petugas berhasil login. Berikut gambar dan penjelasannya:
Gambar 9. Implementasi Halaman Beranda

\section{Implementasi Halaman Penyuratan}

Halaman penyuratan merupakan halaman yang mengelolah surat masyarakat desa. Berikut gambar dan penjelasannya:

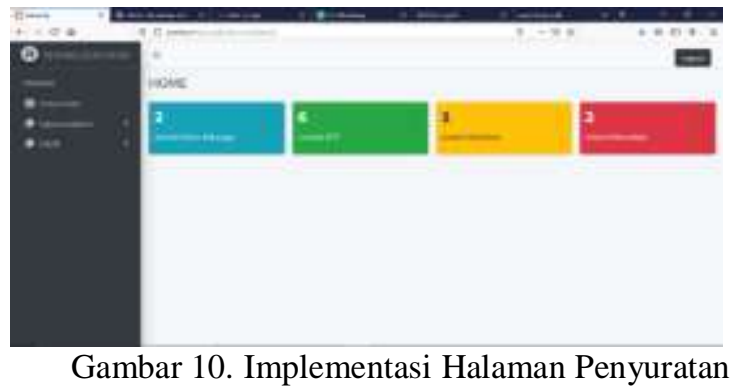

\section{Kesimpulan dan saran}

Tata Kelola Desa Berbasis Web di kantor Desa Sepukur Menggunakan Metode Waterfall selesai dibangun menggunakan bahasa pemrograman PHP dengan framework codeigneter, database MySQL serta berhasil diuji menggunakan black box testing. Aplikasi Tata Kelola Desa Berbasis Web di Kantor Desa Sepukur ini dapat menjadi model pengembangan sistem sebelumnya untuk nantinya apakah akan digunakan atau tidak oleh pihak Desa Sepukur, sehingga ketika sudah digunakan akan bermanfaat untuk mempermudah petugas Desa Sepukur dalam melayani masyarakat dalam pengelolaan surat menyurat, data kependudukan serta pengarsipan surat masuk dan surat keluar.

Aplikasi Tata Kelola Desa Berbasis Web di Kantor Desa Sepukur ini masih jauh dari kata sempurna sehingga perlu ada pengembangan yang dilakukan oleh peneliti selanjutnya, Adapun saran yang dapat disampaikan terhadap pengembangan Aplikasi Tata Kelola Desa Berbasis Web di kantor Desa Sepukur ini yaitu Aplikasi ini masih berjalan di localhost sehingga perlu pengembangan agar aplikasi nantinya dapat berbasis online agar pihak desa dapat mengakses aplikasi dimanapun dan kapanpun. Aplikasi ini juga diharapkan dapat dikembangkan agar lebih kompleks lagi seperti menambahkan fitur pengelolaan lain, contohnya seperti pengelolaan Badan Usaha Milik Desa (BUMDES) dan lain sebagainya, sesuai dengan kebutuhan yang sering dilakukan oleh pihak desa.

\section{DAFTAR PUSTAKA}

[1] Ramadhani, S., Hermawanto, F., \& Mariani, A. (2019). Aplikasi Pelayanan Surat Menyurat Desa Tanah Putih Berbasis Web. Jurnal Teknologi Informasi Indonesia (JTII), 3(2), 54. https://doi.org/10.30869/jtii.v3i2.265

[2] Widyawati, E. (2016). Rancang Bangun 
Aplikasi Kependudukan Berbasis Web Di Desa Kedungrejo Waru-Sidoarjo. Jurnal Manajemen Informatika.

[3] Aditiyawarman, D., Setiadi, D. R., Kumbara, R., \& Umbara, I. (2018). Pengembangan Sistenm Informasi Administrasi Desa Terpadu Pada Desa Karoya Kabupaten Purwakarta. Jurnal Abdimas Bsi, 1(3), 541-553. http://ejournal.bsi.ac.id/ejurnal/index.php/abdi mas/article/view/4059/2544

[4] Arief, M. R., Kom, M., \& Kom, M. (2017). RANCANG BANGUN SISTEM INFORMASI DATA KEPENDUDUKAN DI DESA KATERBAN KECAMATAN BARON NGANJUK Oleh: IRA NUR HAYATI Dibimbing oleh: UNIVERSITAS NUSANTARA PGRI KEDIRI. 1-9

[5] Hunaifi, N., Hikmah, A. B., \& Nurhasan, A. (2019). Perancangan Sistem Informasi Pengarsipan Dan Permohonan Surat Online "Sipadu" Di Tingkat Kecamatan Berbasis Web. JUST IT : Jurnal Sistem Informasi, Teknologi Informasi Dan Komputer, 10(1), 40-51

[6] Dewantara, A. K., \& Mailoa, E. (2019). Implementasi Pemetaan Perilaku Hidup Bersih Sehat Menggunakan Framework CodeIgniter dan Google Maps API (Studi Kasus Dinas Kesehatan Kota Salatiga). Aiti, 16(1), 1-17. https://doi.org/10.24246/aiti.v16i1.1-17

[7] Nugroho, A. (2010). Rekayasa Perangkat Lunak Berorientasi Objek dengan Metode USDP. Yogyakarta: C.V ANDI OFFSET. Retrieved from https://bit.ly/3doKKXJ

[8] Padeli, P., Henderi, H., \& Suyatno, S. (2008). Membangun (E-Procurement) Pengadaan Barang dan Jasa dengan Prinsip Good Corporate Governance dengan Visual UML. Creative Communication and Innovative Technology Journal, 2(1), 69-79.

[9] Pressman, Roger S. (2015). Rekayasa Perangkat Lunak Pendekatan Praktisi Buku I : Adi Nugroho. Yogyakarta: Andi 